International Journal of Child, Youth and Family Studies (2012) 4.1: 479-499

\title{
CAUCASIAN PARENTS' EXPERIENCE WITH TRANSNATIONAL-TRANSRACIAL ADOPTION: A PHENOMENOLOGICAL STUDY
}

\section{Soyeon Park}

\begin{abstract}
This qualitative research explored American Caucasian parents' experience with transnational-transracial adoption. Guided by social constructivism and phenomenology, the goal of this study was to understand how parents perceive and interpret their experience when adopting a child transracially, specifically from China and Korea. Data from in-depth interviews with 17 parents revealed the essence of their experience as embedded in family relations distinctive at various stages of the adoption process. Prior to adoption, transracial adoptive parents possessed well-established ideas about the family and parenthood, which enhanced their commitment and sense of ownership throughout the adoption process. While meeting the child and developing a relationship, parents experienced a complicated mixture of emotions, including tension, anxiety, guilt, and grief. The results also offer further insight into the perspective of American Caucasian parents regarding the cultural socialization of their children. The lack of knowledge and resources regarding the adopted child's birth culture influenced the parents, often resulting in feelings of helplessness.
\end{abstract}

Keywords: transnational-transracial adoption, parenting, culture, phenomenology

Soyeon Park, Ph.D. is Assistant Professor, Department of Child and Adolescent Development, San Francisco State University, 1600 Holloway Avenue SCI 392, San Francisco, California, U.S.A., 94132. E-mail: park@sfsu.edu 
International Journal of Child, Youth and Family Studies (2012) 4.1: 479-499

Trends in adoption in the United States have changed over the years. According to the national data, there are 1.7 million adoptive households, and $2 \%$ of all U.S. children live with at least one adoptive parent (Kreider, 2008). Specifically, international adoption has increased radically in the U.S., creating more multicultural families and contributing to racial and ethnic diversity in the country. As the number of U.S. children available for adoption has declined and the processes of domestic adoption are slow and legally complex (Kent \& Mather, 2002), more adoptions today are international and transracial (U.S. Citizenship and Immigration Services, 2003).

Transracial adoption is the practice of placing a child into a family of a race or ethnicity that differs from the child's birth family (Simon \& Altstein, 1996; Vandervort \& Sanoshy, 2009). It typically involves European American parents adopting children of color. Indeed, 95\% of all U.S parents who adopted children internationally in 2000 were White (U.S. Bureau of the Census, 2000). Although families can adopt children of different ethnic backgrounds through various forms of domestic adoptions, such as foster care and stepchildren from interracial marriages, the majority of transracial adoptions in the United States remain international adoptions (Lee, 2003).

Of the young children adopted annually from over 100 countries, three-quarters are from only six countries, and the top three primary adoption countries are China, Russia, and South Korea, which together made up 57\% of all international adoptions in 2001 (Evan B. Donaldson Adoption Institute, 2002).

The largest number of transracial families created by international adoption involves White parents and Asian children. Nearly 60\% of all children adopted internationally between 1971 and 2001 came from Asian countries (Evan B. Donaldson Adoption Institute, 2002). The Census 2000 special reports showed that about half of the foreign-born adopted children were born in Asian countries (Kreider, 2003).

South Korea has been the primary country for U.S. adoptions in the past. More than 110,000 children were adopted from South Korea between 1955 and 2001, representing 37\% of all U.S. international adoptions in 1990 and 10\% in 2001 (Evan B. Donaldson Adoption Institute, 2002). China has recently become another primary country for international adoptions. The statistics show that over 64,000 Chinese children were adopted by American families between 1999 and 2010 (U.S. Department of State, 2010). Many researchers have studied the impact of the adoption of Asian children into White American families with the primary focus on either the outcomes or the racial/ethnic identity development of adoptees (Lee, 2003).

Various aspects of transracial adoption need further investigation, including the contextual nature of adoption (Palacios \& Brodzinsky, 2010). In particular, it has been difficult to find studies that capture and reflect adoptive parents' perspectives through their narratives. Little is known about these adoptive parents' experiences throughout the transracial adoption process and how they interpret, conceptualize, and renegotiate their family lives (Ishizawa, Kenney, Kubo, \& Stevens, 2006). Given that most adoptive parents have been European 
International Journal of Child, Youth and Family Studies (2012) 4.1: 479-499

American and more than half of internationally adopted children come from Asian countries, more research on transnational-transracial adoptive parents is important to gather further knowledge of their lived experiences embedded in their own unique and individual context. Therefore, this study seeks an in-depth understanding of adoptive parents' perspectives regarding the process of transnational-transracial adoption and parenting. The following research questions guided the study:

1. What are Caucasian parents' experiences with transnational-transracial adoption?

2. How do Caucasian parents conceptualize their parenting and their relationship with their transnationally and transracially adopted child in a cultural context?

\section{Transnational-Transracial Adoption and Parenting}

Becoming a parent is a rewarding yet challenging task. For adoptive parents, parenthood can be even more complex and multilayered as different distinctive issues confront adoptive parents and their children at each stage of the family life cycle (Brodzinsky \& Pinderhughes, 2002). Even for biological parents, the transition to parenthood is a period of normative crisis in which substantial adjustment occurs due to increased daily stress. Becoming an adoptive parent places more demands on the individual and the couple than just those of a new parent because of the unique challenges. Examples of adoption-related tasks parents address include deciding to adopt, adjusting to adoptive parenthood, discussing the adoption and the birth family with their child, and supporting their child's positive self-identity. Particularly, the uncertainty associated with the adoptive waiting period, which can be from a few months to several years, adds more complexity to the transition to parenthood. Issues and challenges may also emerge after adoption and not many parents are prepared for post-adoption problems. In the study by McKay and Ross (2010) for example, Canadian adoptive parents indicated that they had not anticipated the challenges they had to face during the post placement period.

Furthermore, parents who adopt a child from an ethnically different country may experience dynamic and complex family circumstances. When adopting a child across national borders, parents have to raise a child already placed outside of his or her own cultural context. As transnational-transracial adoption cannot be separated from a multicultural family context, parents will need to develop a new identity of their own. McCarthy (1999) found that parents who adopted a child internationally developed multiple identities as parent, adoptive parent, and international adoptive parent connected to the child's birth culture. Parents whose children were different from them in appearance were more likely to identify with and use more cultural practices that connected them to their child's birth culture.

All families experience various life stages that affect all members of the family. In the case of transnational-transracial adoptive families, each family member faces additional tasks at each life cycle stage. One of the significant challenges most transracially adopted children encounter is developing their ethnic identity as they grow up in the culture of their adoptive parents (Lee, 2003; Lee, Yoo, \& Roberts, 2004). Many parents realize it is important for their transracially adopted children to understand and appreciate their own cultural origin for healthy growth and development and encourage their children to develop a bicultural identity (Friedlander et al., 2000). Research shows that parents who more actively promoted discussion 
and exploration of race and culture within the family had children with more positive psychological adjustment and outcomes (Simon \& Roorda, 2000).

Engaging adopted children in cultural exploration and activities may not be an easy task. In general, transracial adoptive parents' racial socialization practices decrease over time (Deberry, Scarr, \& Weinberg, 1996), partly due to the fact that transracial adoptive families often live in a community that does not have easy access to their child's birth culture. In research done by Feigelman and Silverman (1983), many adoptive parents of Koreans encouraged their children to learn about their ethnic heritage, and yet only $17 \%$ of these families lived in communities with substantial numbers of Koreans. This lack of resources and access to the child's birth community can negatively affect the cultural competencies of transracial adoptive parents and the incorporation of the child's birth culture into family life. Many transracial adoptive parents do not have sufficient knowledge about their adopted child's culture, so one of the primary strategies for exposing the child to his or her culture is to have contact with the child's birth community. Cultural exposure will be limited if the family lives in a predominantly White neighborhood. Adoptive parents may have more difficulty promoting enculturation of their children as well as developing their own cultural competency as parents when there is a lack of relevant resources. Transnational and transracial adoption is a relatively uncommon way to achieve parenthood and as such, it may mean a lack of specific role models and resources. Adoptive parents may not develop realistic expectations and their own clearly focused child rearing plans if they don't have enough information and knowledge about the culture of their adopted child.

Research also shows transracial adoptive parents have differing views on race. Parents often show racial ambivalence by embracing both color-blind ideology and racially specific choices (Kubo, 2010). Shiao, Tuan, and Rienzi (2004) found that parents who adopted children from Asian countries often internalize existing racial stereotypes, such as the model minority myth of Asian Americans, and believe that Asians assimilate more easily to mainstream White culture compared to Black children. Some parents apply spiritual beliefs and values that often use a color-blind approach when describing their multicultural family that includes an Asianborn child (Crolley-Simic \& Vonk, 2011).

The social constructivist approach guides this study in its attempt to understand the phenomenon of transnational-transracial adoption through true voices of the research participants. Social constructivists believe that people construct knowledge so as to make sense of their lived experiences, and thus, the meaning-making activities of groups and individuals around social phenomena are of central interest (Lincoln \& Guba, 2003). This approach assumes that all meaningful reality is socially constructed, and the essence of shared experiences can be fully narrated (Crotty, 1998; Marshall \& Rossman, 2006). Transnational-transracial adoption has a great effect on not only the adopted child, but also the adoptive parents. Knowledge, expectations, and meanings that these parents possess prior to transnational-transracial adoption are thus reconstructed, and negotiated as they live their new experiences. Such constructs are deeply embedded in the perspective of each person. Therefore, in addition to our empirical findings regarding adopted children's outcomes and development, it is vital also to accumulate further understanding of the transnational-transracial adoptive parents by listening to their individual stories and their personal interpretations of that experience. 
International Journal of Child, Youth and Family Studies (2012) 4.1: 479-499

\section{Methodology}

A qualitative research methodology is an appropriate approach when studying issues of context, dynamic processes, and the subjective perspectives of individuals (Marshall \& Rossman, 2006; Rossman \& Rallis, 2003). The foci of this study were Caucasian parents' experiences with and perceptions of their transnational-transracial adoption. Among various qualitative methods, phenomenology was chosen because this study was meaning oriented and expressly interested in the essence and structure of a specific experience (Merriam, 1998; Patton, 2002).

Phenomenological studies seek to understand the deep meaning of an individual's experiences and how he or she articulates these experiences (Rossman \& Rallis, 2003). The primary source of knowledge this study sought was the participants' own descriptions and interpretations of their experience with transracial adoption. Transnational-transracial adoption, the central phenomenon of this study, was explored in order to gain a new understanding of what common experiences these participating parents shared.

\section{Participants}

The data were collected from 17 qualitative interviews with 9 mothers and 8 fathers in 9 transnational-transracial adoptive families. More specifically, these families adopted a total of 11 children from China or Korea. Of this group, 7 Chinese children were adopted by 6 families, whereas 3 families had adopted a total of 4 children from Korea. For those couples who had adopted more than one child, the second adopted child came from the same country. All children from China and two of the four Korean adoptees were girls, with only two adopted children being boys.

Although generalization is not the fundamental goal of qualitative studies, an appropriate sample size that allows findings to be confirmed has always been a key issue to address. Phenomenology involves the close study of a relatively small number of participants who have all experienced the phenomenon under investigation. Usually this group ranges between 5 to 25 individuals with 10 participants considered to be a reasonable size (Creswell, 2007). Speziale and Carpenter (2007) suggest that 10 to 15 participants is adequate to provide rich descriptions of a phenomenon. Kvale and Brinkmann (2009) note that, in most interview studies, the interviews tend to total around 15. The number of participants in this study, therefore, was deemed to be appropriate and sufficient for the particular research method chosen for this study.

Participants were recruited through criteria-based, purposive sampling. All participating parents had experienced the central phenomenon and expressed their interest and willingness to invest the necessary time to complete interviews (Moustakas, 1994). The major criterion was (a) the participants had adopted a child from China or Korea, two primary countries for international adoption, and (b) their own ethnicity is Caucasian. Other demographic criteria, such as reasons for adoption, the number of adopted children, age of the participants or their adopted children, and the length of post-adoption time, were not considered in the selection of participants because the primary focus of the study was on whether the participants had experienced the actual phenomenon. Therefore, detailed demographic information was not gathered as part of the data 
International Journal of Child, Youth and Family Studies (2012) 4.1: 479-499

collection process although most participants did naturally describe the specific contexts and backgrounds of their transnational-transracial adoption experience during the interviews.

All participants in this study were heterosexual, married, and Caucasian. They were each at various stages as a transnational-transracial adoptive family, ranging from 1 month to 10 years of time spent with their adopted child. Out of the total 9 families, 3 families had had at least one biological child prior to adopting a child internationally. With the exception of one family, both the mothers and the fathers were interviewed to gain full perspectives from both parents. Each interview was handled separately, and the unit of analysis was one of the individual, not the couple.

\section{Data Collection and Analysis}

Upon IRB approval, 5 participants were recruited through a local child care center in rural New England. The remaining 12 participants were recruited through snowball sampling. All 17 participants were interviewed face-to-face by the author. The interviews were arranged by e-mail or phone and took place at a location convenient for the participants, such as their home, office, or a local coffee shop. The length of the interviews varied from 50 to 100 minutes. There was no compensation provided for participation.

Participants received and signed an informed consent form at the beginning of the interview. Open-ended questions were used for the interviews, beginning with family history and the context for adoption. Participants were encouraged to illustrate their stories in their own words and probing questions followed, when necessary. Fathers received more probing questions, as their answers tended to be short and refer to their wives for more information. Interviews with the fathers were also relatively shorter in duration than interviews with the mothers. During both the interviews and the later analyses, I practiced bracketing by setting aside my own knowledge or preconceived ideas and biases about transnational-transracial adoption so as to understand the phenomenon through the perspectives of the participants who experienced it (Mouskatas, 1994). I audiotaped all interviews and consequently, two external transcriptionists transcribed the recordings verbatim. I reviewed the initial transcripts by listening to all the tapes and correcting any perceived errors.

Data analysis of the study followed several precise steps informed by Moustakas’ (1994) modification of the Stevick-Colaizzi-Keen method, which was suggested by Creswell (2007). As a first step, I wrote a researcher narrative prior to the interviews, describing my own personal perception of transnational-transracial adoption. Next, after reading the transcribed data closely several times, I began to highlight significant statements, sentences, or quotes that appeared important for understanding the participants' experiences. I then clustered the meanings into themes to achieve phenomenological reduction (Marshall \& Rossman, 2006). Through this analysis process, I was able to extract 152 significant statements that I later grouped into 26 meaning units. Special attention was paid to develop a structural description to connect the identified meanings and explain the ways in which the experiences happened.

Trustworthiness and the rigor of the study were both enhanced through a bracketing of the researcher's biases as well as a triangulation of the data collected by reframing, repeating, 
International Journal of Child, Youth and Family Studies (2012) 4.1: 479-499

and expanding the questions asked during the interviews. This process allowed the data to be examined in different ways (Rossman \& Rallis, 2003). Field notes and a reflective journal were also used to offer multiple data sources. Further, all analyses and findings were shared with another colleague in the same field for peer debriefing to enhance the data verification.

\section{Findings}

A phenomenological analysis of the 17 interviews revealed several themes after synthesizing and clustering “the invariant meaning units” (Moustakas, 1994, p. 122). Most participants described their experience chronologically as it related to the actual process of adopting a child. They incorporated reflections and interpretations of that experience while narrating it. The experiences of adoptive parents were distinctive at each phase of the process deciding and planning for adoption, meeting and bringing the child home, and lastly, establishing a relationship with the child that was associated with the adjustment to the new family structure.

In the following section, the essence of the transnational-transracial adoptive parents' experiences, as described and interpreted by the study participants, is portrayed in a chronological manner that captures their unique experiences at each phase of the process. In the presentation of the results, all participants are identified by gender and number, such as Mother \#1 and Father \#1. The identical number indicates that the interviewees belong to the same family. All names referenced by the participants during their interviews were replaced with pseudonyms, and descriptions such as "the child" and "the spouse" were then added in parentheses next to each pseudonym.

\section{Aspiration for parenthood: Planning for adoption}

\section{Commitment to parenthood}

The study's transnational-transracial adoptive parents had various individual circumstances and different reasons for adoption. However, they shared a common experience the persistent, hardworking, and complicated process to achieve the parenthood they dreamed of having. Participants expressed their strong motivation for and investment in becoming a parent. Although the participants who had experienced infertility chose adoption as an alternative way to become a parent, there were also several participants who had a desire to adopt at an early stage in their marriage, regardless of their own fertility. In addition, participants' interpretations of parenthood and adoption often connected to their own childhood and family backgrounds. One parent stated, "I always wanted to adopt because it was just a culture that I had grown up with. My grandmother, who lived next door to me, had six kids of her own 'cause everybody had huge families” (Mother \#5).

Starting a "family" and having a "family" meant a lot to all participants in this study. The concept of family was understood within the paradigm of parenthood, which could only be fulfilled by having a child. Without a child, that paradigm was incomplete. Bringing a child to a couple was crucial for them to feel wholeness and completeness as a family. One father shared his thoughts as, "We talked about the desire to have a family, I mean, to have children and that was an important part of early conversations" (Father \#7). This perspective was supported by another father's statement: 
International Journal of Child, Youth and Family Studies (2012) 4.1: 479-499

It's a family. When you have two kids, you know, you're a family, when you have three kids, it's really a family.... It makes you feel like, "Wow, this is really a family. This is what a family should be.” Sitting around, all having dinner together and everyone is being pleasant and enjoying dinner, it's so nice. There's just nothing else like it. (Father \#5)

All mothers had a definite desire for motherhood from the very beginning of, or even prior to, their marriages, which made adoption a natural option, as evidenced by statements such as, "I always knew I wanted children" (Mother \#6) and "I think somehow I had this seed in my mind that if I can’t, I mean I knew if I didn’t get pregnant, I knew I would adopt” (Mother \#9). Fathers also believed in the importance of family, but it seemed that the mother's desire was more influential. When one spouse was more devoted and committed to parenthood compared to the other, the adoption decisions were not easily made. One mother addressed the conflicts she had experienced with her spouse regarding the adoption decision. She shared her experience in that it had required more effort to convince her husband. This father's perspective was not included in this study because he didn't participate in an interview.

Shortly before we got engaged, we were talking about children and he told me that if for any reason I couldn't have children, he wanted to be clear with me that he did not want to adopt.... I said, “I don't have any reason to believe that I can't have children, but I can't sign a contract or promise you that if we don't get pregnant, then there'll be no kids. I mean I want to be a mother and I hear what you're saying, but if that happens we'll just have to deal with it then, because I can’t promise that.” (Mother \#9)

This mother faced further conflicts when the couple was experiencing infertility after getting married. She kept after her husband until they finally decided to adopt a girl from China:

He was very clear he wouldn’t, doesn't want to adopt and I was very clear that I wanted to be a mother more than anything else in the world.... I said to him, "What I want more than anything else is to be a mother. And you have what you want and now you're standing in the way of me getting what I want.” (Mother \#9)

\section{Sense of ownership and control}

Transnational-transracial adoptive parents appear to have very specific beliefs and plans about their family structure and relationship. Anxiety and fear associated with the inability to gain full ownership as a parent often stems from their strong sense of commitment to rearing a child and establishing a family. Most of the parents in this study explained that they had made their decision to adopt internationally partly due to the fear of a possible future involvement of biological parents in a domestic adoption. One mother shared her concerns, "People will adopt in this country and then months later or years later, the biological parents come back and they claim. And the judges always seem to favor the biological parents and then families are ripped apart" (Mother \#7). Another parent confirmed the same view, "I had no interest in getting an American baby, because [of] the one percent chance that the parents change their minds and you lose the kid, right? That's never going to happen with a Chinese kid” (Father \#6). 
International Journal of Child, Youth and Family Studies (2012) 4.1: 479-499

The adoptive parents' decision-making processes were also affected by their desire to own and control the process and outcome. The final decision for international adoption and selection of the specific country was based on the participants' well-structured ideas and concepts in terms of what type of family they wanted to have. It was important for the participants to be able to avoid an uncertain timeline and all unknown factors that could significantly affect their plans. The following statements exemplify these considerations:

For domestic adoption, most birth mothers want contact, and they want letters and pictures for 18 years. And Don [the spouse], in particular, had a really hard time with that and just said, I'll never feel like this child is my own if I have to report back every year.... This agency in Florida, they literally told us, "you can get a phone call, like tomorrow, that a baby is being born and in 48 hours it's gonna be your baby.” Like no notice. No notice at all. And I just said, “There’s no way. I can’t.” (Mother \#3)

In the domestic program, what they would do is they gather information on us as a couple, and then they presented it to perspective birth mothers who were looking for placement of infants.... There's no real timeline that we can count on. It could be for five years and [we] never end up with a child or it might be five weeks....We waited to have children to start with, and then we went through this long period. We felt certain urgency. We wanted to have children while we still could have the energy to keep up with them. (Father \#1)

For parents who already had their own child, it was particularly important to keep and maintain the harmony of the current family structure intact. Hence, the decision to adopt was based on the availability of a child who had the desired characteristics, such as gender, age, and health. Participants in this study began with a wide range of options and became more selective as they learned the available options that met their criteria. It became "kind of like a process of elimination” (Mother \#3). The following excerpts show how the pre-established ideas of transnational-transracial adoptive parents about family connected to their decisions:

I had two sons and I just always wanted a daughter... I was sort of really reluctant to adopt domestically from this country... It takes years and years and years to get a small child, I didn't want to adopt a child who is older than the children I already had. I wanted to keep the birth order of the children the same. (Mother \#4)

We knew we wanted to have two children and we wanted to participate in a program that we would be able to do again because we had, at that point, made the decision that we'd like both of our children to be born in the same country, so that we could really focus on their heritage and learn about that. (Mother \#1)

\section{The long-awaited moment: Meeting the child}

Tension and anxiety accompanied by emotional and physical reactions.

Participants provided detailed and vivid descriptions of their memories related to the moment they first met their child. Parents who chose to adopt a child from China were required to go to China to take the child home. One parent recalled, "It was an eye opening experience. 
International Journal of Child, Youth and Family Studies (2012) 4.1: 479-499

That's a whole another world, definitely. And it's a very emotional experience. I mean, really. It's very tough emotionally, to take a person out of their culture and out of their world" (Mother \#5). For adoption from Korea, parents did not need to go to the country since there was an escort program. An assigned adult accompanied the child on the flight from Korea to the United States, and the adoptive parents then met the child at the airport. In both cases, the participants experienced intense physical and emotional tension. Parents interpreted their reactions as stemming from not knowing what to expect. For the parents who travelled to China in particular, their anxiety was significant, given that they were in a foreign country and having to handle a language and social system with which they were not familiar. In the words of one couple:

We were incredibly anxious, and we didn’t eat breakfast. We were hanging in the hotel lobby first thing in the morning, just waiting. I remember clearly, she [the spouse] was just sitting quietly. She was dealing with her stress, and I couldn't sit still. So I'm walking around the lobby, I'm walking outside.... It was a strain. We were nervously excited, um, and it was quite emotional. (Father \#4)

My husband and I both dealt with it differently, but I was really swallowing. I was having to keep bottled so much up in me, and then I, between the jet lag and that, I went through a lot, and I never experienced anxiety here in the United States, so I didn't know what was going on, but I had incredible dehydration, inability to swallow and that was all physical signs of the anxiety, combined with jet lag problems and lack of sleep. In China, [on] the whole trip I went through that and of course I'm feeling terribly guilty because I can’t be physically there for her [the child] or my husband. (Mother \#4)

Although parents adopting a child from Korea did not have to travel to the country, their experience of meeting their child was also intense, as supported by many participants' statements such as, "I was pretty nervous. Not knowing what to expect, it certainly was an emotional moment” (Father \#2). Another father used an analogy, “I don’t know what it's like to see my wife giving birth and having a newborn, but I imagine that it would be similar. It was quite something” (Father \#1). Whether their emotion was a positive excitement or nervous anxiety, all participants experienced a strong tension. Welcoming a child into the family for the first time is a private matter, but usually it takes place in a very public place for adoptive parents. One father shared that, "Somebody walks up to you and hands you a baby... I think that would be kind of challenging itself, but the fact that you're doing it in a busy international airport was just odd" (Father \#3). Similar emotional experiences were evidenced in other parents' comments:

I was extremely emotional when we knew the plane was there, I was very teary. I think that the wait and thinking about all that we had wanted for so long and to really have that come to fruition. It was just really overwhelming, and I was anxious. I was very anxious. (Mother \#1)

We saw on the board that the flight had landed, and then we saw all the people coming off and off and off. And we waited and waited and just, she wasn't there... and there are a lot of babies coming off, too. Is that her? And it was awful. My physical reaction was, I had to go to the bathroom. I kept saying like, "Oh my God, I have to go to the bathroom now”... I didn't want to miss it. And then I'd run back and, you know, but when she 
International Journal of Child, Youth and Family Studies (2012) 4.1: 479-499

came, it was like I immediately knew... I just started to cry. We just, I just started to cry. I didn't even know what to say. There she is, you know. I just couldn't, I just couldn't believe, there's that baby in the pictures, there she is and she’s here now. (Mother \#3)

\section{Grieving alone, grieving together.}

Adoption involves many emotions, especially the sadness and compassion that comes from various kinds of loss. Throughout the process of adoption, particularly at an early stage, these parents experienced a grieving process to some extent. It occurred in a variety of forms and involved many people who are part of the context. When the adopted child is older, the emotion that child brings can be substantially influential, which makes the initial adjustment more difficult. One father graphically illustrated it by stating:

About 4:30 in the morning, she was in her bed sobbing. And I got up with her and that was how we started our life in America. And she was going on and on in Chinese, she was telling me, “Take me back to the airport, put me on a plane, send me back to China." And she was just sobbing and going on and on in Chinese, she didn't want to be here. She wanted to go home, and I cried with her and, and that morning she, she actually allowed me to comfort her after we were crying together, and she sat in my lap and just hugged me and cried for an hour and a half, and she snapped out of it and, and really never went there again. Um, but, you know, that's how we started our life together here. (Father \#4)

One couple, in separate interviews, described how such grief could be reflected in their later interaction with the child:

She [the adopted child]'s out of the blue and said, "I hope no one takes me away." So, she remembers what happened. She remembers, and she probably remembers less and less details. If she saw the face of her mother and father that raised her, she'd probably recognized them. (Father \#5)

She [the adopted child] came straight out and said to me, "Mom, is anyone gonna have to take me away?” Now, for a two-year-old to be asking me that, it's just heartbreaking that this would even be part of her psyche. It was, it was so ingrained. It affected her so much that it just stayed with her for a very long time. (Mother \#5)

Adopting a child may affect other members of the family as well. When parents already have their own child before adoption, it becomes natural that this child is also made a part of the whole process. One mother shared a story about how her biological daughter, who was a preschooler, tried to make sense of the adoption process and how she grieved for the loss of the imagined boy whom she thought would be her younger brother:

We told Cristina [the biological child] that she was gonna get a brother, 'cause that's what they told us. And when we got the referral, it was a girl... She had named her baby brother. She named him Oliver. I think in her own mind, she had started to envision a life with her brother. And then she actually got pretty upset and said, "Who's gonna take care of Oliver?" like, "Who in Korea is gonna take care of Oliver?”, and then we had to explain. "Well, there is no Oliver”, you know. (Mother \#3) 
International Journal of Child, Youth and Family Studies (2012) 4.1: 479-499

This same mother added another post-adoption episode: “One morning, Anna [the adopted child] was lying on the bed just screaming, crying. Cristina was there, 'mommy, my sister's sad for her foster mother. She’s crying for her foster mother', she said” (Mother \#3).

Parents' empathy and grief may expand to other significant people in the child's preadoption period. Imagining the part of that child's life in which they were not included appeared to bring strong emotions to adoptive parents. The following statements juxtapose these parents' experiences:

We spoke to his [the adopted child's] escort through an interpreter, and she just kept telling us about how everybody was so sad when he left... I don't know that I was feeling sad, I felt so compassionate, wanting to really be able to say to his foster mother, "thank you so much" for the interim care that she had given... His life really didn't start when he came home to us. So it was very, very emotional when he came home. (Mother \#1)

They make you write a dear birth mother letter, which was probably the hardest part of going through all of this, I made Don [the spouse], I said, "You have to write it. I can't, it'd be too upsetting to me to write the dear birth mother letter, you write it and then I'll add to it.” (Mother \#3)

Moreover, meeting adult adoptees or listening to other people's adoption stories often brings new emotions to adoptive parents through empathy. One mother shared her experience:

We just went to a Korean culture dinner. It was run through our agency, and we met with Korean adult adoptees, and you hear their thoughts about getting to meet their birth parents or their foster parents. It was intriguing and heartwarming. I mean, it's emotional, I wouldn't say that it's really sad for me to think about it. In some ways it is. Because there is, in part, there's some grief that goes along with it, for all of us. (Mother \#1)

Adoptive parents also experienced grief when their relationship with their adopted child was different from what they had pictured. Being rejected by the child in particular, had a significant effect on these parents. When there was much anger and rejection from the child, parents seemed to experience even stronger emotions, a mixed feeling of sadness, disappointment, and guilt.

I was prepared for much more crying and sadness, which she really didn't, she just was angry...Y You know that she's hurting and you feel terrible about what she's going through, and you feel terribly guilty.... How can I take this child away from where she seems to be so happy? I knew she had no choice in it... She's really outgoing and real social. And she would go to another American... it was just deliberately, I think, trying to be hurtful or trying to test us, go on their lap and just be like "See, that person's better than you are." So, that kind of rejection really hurt me, and I had to keep it inside. It really bothered me. I wasn’t prepared for that, I was prepared for a lot more clinginess. (Mother \#4) 
International Journal of Child, Youth and Family Studies (2012) 4.1: 479-499

\section{Goodness of fit: Relationships in the making}

\section{The Multifaceted culture of the family}

Prior to adoption, all participants considered the multicultural aspect of the family they would create by adopting a child transnationally and transracially. However, it appeared that more concrete thoughts and experiences occurred after they began their lives with the adopted child. When the parents interpreted their home culture and the multicultural aspects of their family, it did not involve a simple Asian and Caucasian dichotomy. In many cases, adoptive parents already had their own element of cultural diversity, and the new culture of the adopted child that was added to the existing structure, resulting in a more complex environment. The following statement exemplifies a Jewish mother's interpretation of the complex culture in her adoptive family:

It's important to me that she, along with her Chinese identity, has the Jewish identity.... I think of our culture as having three cultures. In some ways, almost a fourth, but a little, I think of us here, um, American, we're Jewish, and we're German-Jewish, which is, with Judaism there, you know, German-Jewish has its own stuff and I increasingly think of us as Chinese. (Mother \#9)

Many adoptive parents emphasized that there were already various cultural components within their family prior to transnational-transracial adoption. The following excerpt indicates this adoptive parent's acknowledgement of diverse cultures that existed in his family:

I'm Jewish. Jane [the spouse]'s not. Her mom is from France. Christianity is a very, very strong element to the French social culture, the whole foundation, a lot... I have these things called "life lessons" just general good ideas, do the right thing... So, you have a lot of philosophy, and you have a lot of superstition in Chinese culture. We've been going to the Chinese culture day, we do something Chinese now. (Father \#5)

His wife supported his perspective in a separate interview:

We're a multicultural family anyway. Andy [the spouse] is Jewish. His grandfather was a rabbi... So we have traditions from both of our families that we always did anyway. And, now that we have Shirley [the adopted child], now [we] do Chinese New Year, you know. We just added more to traditions to the ones we already had. (Mother \#5)

\section{Situated between confidence and helplessness.}

Transnational-transracial adoptive parents tried to understand and learn about their adopted child from the information they had. All parents in this study described themselves as committed, competent, and confident parents. However, in establishing a relationship with their adopted child, they experienced difficulties in applying their own parental knowledge and strategies. Upon the child's arrival, parents felt that they needed to catch up with their child promptly. The process included emotionally bonding with the child as well as improving the child's health when they felt the child "really was behind with everything” (Mother \#6). Most 
parents wanted to form their attachment quickly and even felt a sense of urgency, which was well expressed in the following statements:

I feel like the bonding is really coming along, but it's not there. I would never tell anybody that it's normal... I feel like a sense of urgency, 'cause I feel like the bonding attachment has to be pretty good before she hits teenage. (Mother \#4)

When issues and problems with the adopted child were present, parents randomly attributed them to the individual child's characteristic or cultural differences. One father commented, "I don't know if this is common for a lot of Asian cultures, or just China, or just this family, but there didn’t seem to be affection” (Father \#5).

Parents often felt confused and unsure of their approach, resulting in a sense of failing and helplessness, because they “didn't always know what to do or were feeling not successful” (Father \#8). Even for the experienced parents who had raised their own biological children, parenting became a challenging task that required new skills and practices as one mother claimed, "My mission as a parent is really big right now" (Mother \#8). One parent commented that he had to consciously remind himself that he needed to be proactive and be loving and caring to overcome the confrontational circumstances when "there was a lot of anger and resentment". He described it as, "We just showered her with love and not that that was always easy because, with her anger, she would pull us into confrontational kinds of situations” (Father \#4).

In the relationship with their adopted child, many parents perceived adoption as a vulnerable factor and treated the child in special ways. This was more explicit in their early relationship. The following statement exemplifies this experience:

I was very careful in choosing my words and very careful with my expressions and even my facial expressions, very careful to not scare her. I actually treated her differently than my other kids [biological children] because I wanted to make sure that I didn't scare her, knowing she was already scared... Now she gets treated like everyone else. (Mother \#5)

In the area of parenting related to enculturation of the child, transnational-transracial adoptive parents had less confidence and acknowledged that they had only limited knowledge about their child's birth culture, as evidenced by one mother's statement, “I'm not Korean, I'm not gonna feel comfortable doing that [teaching Korean culture to the child]. It's not my culture and how dare I represent what Korean culture is. Like, who am I to do that?” (Mother \#3).

While all parents had a sincere desire to encourage their adopted child's exposure to his or her birth culture, they did not have concrete plans for doing so. Parents hoped that this cultural learning would happen naturally when the child showed more interest. One parent commented, "He [the adopted child] does occasionally show some interest in Korean culture, but not a whole lot. So we tried to do some of that [cultural activities], but over the past several years it's just, you know, tried less and less” (Mother \#1). Transnational-transracial adoptive parents did not want to "force" cultural engagement if they did not observe a strong interest from the child. Cultural activities incorporated by the adoptive parents into the home were limited to books, 
International Journal of Child, Youth and Family Studies (2012) 4.1: 479-499

food, and holiday celebrations. One mother admitted, "I can't deny the fact that we're raising our children on some level as American children” (Mother \#7).

Participants addressed their awareness and expectations of possible obstacles and challenges in the future that related to transnational-transracial adoption, including a child's racial identity. One father mentioned, “Even if she wasn’t Chinese, just the fact that she's adopted, you have very common adoptee problems. That's the way it is, and when you adopt a child from another culture, there will be more” (Father \#8). One mother also shared, “I'm worried about her waking up one day and she says, 'What's the deal? Why am I in this situation? What happened? What, why, why me?’ and it’s going to be tough” (Mother \#5).

Seeking alternative role models whose ethnicity is the same as that of the adopted child was a common strategy among transnational-transracial adoptive parents. Parents who adopted more than one child from the same country intended to support the child's connection to the birth culture by having a sibling who came from the same ethnic background. That way, if there was something that they were "not getting as American parents, or adoptive parents, somehow they [siblings] could work with each other” (Mother \#1).

\section{Discussion}

The findings of the current study confirmed that Caucasian parents' experiences regarding transnational-transracial adoption are grounded in multiple contexts. Parents who participated in this study appeared to possess well-established ideas about the family and parenthood prior to adoption. However, transnational-transracial adoption challenged the parents' previous conceptualizations of family and parenthood and complex emotions arose surrounding how to bond with the adopted child.

One of the primary reasons for deciding to adopt a child internationally was "feeling safer in international adoption" (Jacobson, 2008, p. 37) because the parents could avoid the possible involvement of the birth parents. The parents' desire to keep their own family intact and protected by avoiding domestic adoption was later replaced by a complicated mixture of emotions including tension, anxiety, guilt, and grief as they met the child for the first time and established an initial relationship. Previous research has indicated that adopted individuals experienced loss and grief-related emotions (Brodzinsky, 2011). The results from this study imply that adoptive parents experience mirrored emotions. More studies to capture adoptive parents' experienced feelings should be added to the current literature on transnationaltransracial adoption.

Transnational-transracial adoptive parents attempt to make sense of their experience and develop socially constructed meanings through interacting and negotiating with their family members, friends, neighbors, and community. For example, parents in the current study had various perspectives regarding understanding and interpreting the multicultural aspect of their family, from color-blindness to authentic multicultural understanding, which seemed to change over time and be influenced by others. One father mentioned, “One of Susan [the spouse]'s friends said, 'Oh, you all look so white.' And I just thought that was strange, I don't know what that means, I didn’t know how to take” (Father \#3). Given that both race and ethnicity are 
socially developed and maintained concepts and that racial identification in particular tends to reflect power relations between whites and people of color (Cornell \& Hartmann, 1998), comments on race imposed by other people can influence adoptive parents' ideas of their own transnational-transracial family.

The color-blind approach was emphasized when parents tried to pay full attention to the individual child they had adopted and understand their family as a focused unit. One father claimed, “I rarely think twice about his being Korean, you know. He’s just my son” (Father \#2). For some parents, transnational-transracial adoption made them more aware of diversity issues in society. One parent illustrated how transnational-transracial adoption directly influenced family relationships with his biological children so as to promote and practice diversity:

Bringing Lin [the adopted child] into that, for us, has been kind of walking the walk that goes with the talk and now, in every way promoting that with our kids and this whole idea of cultural diversity and understanding differences and really reaching out beyond our comfort zone... So we're able to actually have some interesting cultural conversations that we couldn’t have had, just from the presence of Lin. (Father \#4)

Throughout the adoption process, the parents reconceptualized their definition of family, which also shifted the paradigm for their own identity as parents. One mother noted that both parents and children needed to revisit their ethnic identity to become a harmonious family:

We have this tri-cultural family, and I'm saying to her [the adopted child], I adopted you and you didn't have a say in it, I brought you home, I converted you...Y You were born there, I'm bringing you here, and I'm asking you to become American and Jewish. So I feel like, by virtue of my having adopted you, it's not just that I'm gonna make sure you know something about where you came from, but I'm gonna become somewhat Chinese. And if you can be Jewish, then I can be Chinese. (Mother \#9)

Despite the fact that all parents in this study expressed their intention to incorporate and maintain the culture of the adopted child, there was ambivalence about which aspects of culture they can keep. Their approach was close to "cultural tourism, the selective appropriation and consumption of renovated cultural symbols, artifacts, and cultural events as a means of constructing identity for adopted children” (Quiroz, 2012, p. 528). This is also due to limited support systems and role models for embracing their child's birth culture. Although the parents in this study had a wide range of social support networks available, most undertook parenting practices with little or no contact with the child's birth community. This lack of knowledge and resources regarding the adopted child's birth culture influenced the parents in this study, producing feelings of helplessness. This is consistent with the previous research that implies that limited resources, along with the perception of Asians as being more accepted and assimilated (Ishizawa et al., 2006; Shiao et al., 2004; Zhang \& Lee, 2011), can influence transnationaltransracial adoptive parents. They may then downplay their adopted child's race and culture (Bergquist, Campbell, \& Unrau, 2003; Vonk, Lee, \& Crolley-Simic, 2010).

The findings drawn from this study can be linked to a few suggestions about practice in supporting and working with transnational-transracial adoptive families. First, it is important to 
acknowledge that adoption is a lifelong process and transnational-transracial adoptive parents may encounter their own psychological stressors unique to adoption. Long-term, ongoing counselling that can mitigate the negative effects of adoptive parents' emotional issues, especially during the "post-adoption” stage, are needed. Adoption agencies can either house such services or develop the infrastructure to help adoptive parents navigate available resources in their local communities. Creating informal networks of adoptive parents who may share many aspects of transnational-transracial adoption (e.g., child's age, country, gender) can be also facilitated by adoption agencies.

Second, comprehensive training sessions in culturally competent parenting strategies and cultural socialization should be provided both before and after adoption. When transracialtransnational adoptive parents live in a less diverse neighborhood and there is limited contact with people who are from the same cultural background as their adopted child, it is especially critical to ensure that there are sufficient resources for adoptive parents to learn the child's culture. Programs that connect adoptive families with adult adoptees or recent immigrants from the country of the adopted child would be beneficial.

Finally, practitioners who directly work with transracially adopted children and their families should treat each adoptive family individually in order to increase open communication and effectively relate with the family. By encouraging transnational-transracial adoptive parents to reflect on their unique family context and deepen multicultural understandings, practitioners and parents together can identify and locate appropriate services and resources for the adoptees' healthy growth and development.

\section{Conclusion}

The present study attempted to explore Caucasian parents’ perspectives regarding transracial adoption. By providing rich descriptions of the phenomenon, the study attempted to capture the essence of transnational-transracial adoptive parents' lived experience in the context of both culture and socially constructed meaning. These parents' reflections of their adoptive experiences offer valuable information to the literature for understanding the complexity of transnational-transracial adoptive parenthood and its relationship to cultural and ecological contexts. The presentation of these interviews indicates that Caucasian parents have unique experiences throughout all phases of transnational-transracial adoption. The meanings behind establishing a multicultural family by adopting a child internationally are socially constructed as well as embedded in the existing family relationships and the parents' views on the family, parenthood, and culture.

One of the valuable aspects of this study was that it provided unique insight through interviews with both mothers and fathers (with the exception of one family). Although the analysis was individual-based, it is important to note that all eight couples tended to share similar stories or episodes to illustrate their experience. They often included their perspectives of the other spouse with direct quotations. It is natural that memorable incidents and unique moments influence both people in this circumstance. However, it may also be the case that meanings and interpretations of the experience emerge and are further refined through social co-construction since couples experienced the phenomenon together. Bergquist, Campbell, and Unrau (2003) 
reported similar research findings, indicating mothers and fathers are similar in their perceptions about their experiences with transnational-transracial adoption. Further research that includes adoptive couples as a unit of analysis, or investigates the perspectives of fathers more closely, will add valuable knowledge to the current literature of transnational-transracial adoption.

The findings of the present study must be understood within its limitations. First, the participants resided in a rural area of New England, which is less diverse compared to other parts of the United States. Although this study intended to focus implicitly on transnational-transracial adoptive parents who may not have easy access to diverse cultures, various ecological contexts that influence transnational-transracial adoptive parents must be carefully considered when interpreting the findings of this study. Second, transnational-transracial adoption is common among gay and lesbian couples, but this study only included heterosexual, married couples. Therefore, the results here should be interpreted within this limitation as gay and lesbian parents' experiences with transnational-transracial adoption might be substantially different. In order to explicate the full phenomena of transnational-transracial adoption, future research should explore parents' perspectives further by including the voices of various types of transnational-transracial adoptive families. 
International Journal of Child, Youth and Family Studies (2012) 4.1: 479-499

\section{References}

Bergquist, K. J. S., Campbell, M. E., \& Unrau, Y. A. (2003). Caucasian parents and Korean adoptees: A survey of parents’ perceptions. Adoption Quarterly, 6(4), 41-58.

Brodzinsky, D. M. (2011). Children’s understanding of adoption: Developmental and clinical implications. Professional Psychology: Research and Practice, 42(2), 200-207.

Brodzinsky, D. M., \& Pinderhughes, E. E. (2002). Parenting and child development in adoptive families. In M. H. Bornstein (Ed.), Handbook of parenting: Vol. 1. Children and parenting (pp. 279-311). Mahwah, NJ: Lawrence Erlbaum.

Cornell, S., \& Hartmann, D. (1998). Ethnicity and race: Making identities in a changing world. Thousand Oaks, CA: Pine Forge Press.

Creswell, J. W. (2007). Qualitative inquiry and research design (2nd ed.). Thousand Oaks, CA: Sage.

Crolley-Simic, J., \& Vonk, M. E. (2011). White international transracial adoptive mothers' reflections on race. Child and Family Social Work, 16(2), 169-178.

Crotty, M. (1998). The foundations of social research: Meaning and perspective in the research process. Thousand Oaks, CA: Sage.

DeBerry, K. M., Scarr, S., \& Weinberg, R. (1996). Family racial socialization and ecological competence: Longitudinal assessment of African-American transracial adoptees. Child Development, 67(5), 2375-2399.

Evan B. Donaldson Adoption Institute. (2002). Research: Adoption facts. Retrieved from http://www.adoptioninstitute.org/research/internationaladoption.php

Feigelman, W., \& Silverman, A. (1983). The long-term effects of transracial adoption. Social Service Review, 58(4), 588-602.

Friedlander, M. L., Larney, L. C., Skau, M., Hotaling, M., Cutting, M. L., \& Schwam, M. (2000). Bicultural identification: Experiences of internationally adopted children and their parents. Journal of Counseling Psychology, 47(2), 187-198.

Ishizawa, H., Kenney, C., Kubo, K., \& Stevens, G. (2006). Constructing interracial families through intercountry adoptions. Social Science Quarterly, 87(5), 1207-1224.

Jacobson, H. (2008). Culture keeping: White mothers, international adoption, and the negotiation of family difference. Nashville, TN: Vanderbilt University Press. 
International Journal of Child, Youth and Family Studies (2012) 4.1: 479-499

Kent, M. M., \& Mather, M. (2002). What drives U.S. population growth? Population Bulletin, 57(4), 1-44.

Kreider, R. M. (2003). Adopted children and stepchildren: 2000 (CENSR-6RV). Retrieved from http://www.census.gov/prod/2003pubs/censr-6.pdf

Kreider, R. M. (2008). Living arrangements of children: 2004. (Current Population Reports, pp. 70-114). Washington, DC: U.S. Census Bureau.

Kubo, K. (2010). Desirable difference: The shadow of racial stereotypes in creating transracial families through transnational adoption. Sociology Compass, 4(4), 263-282.

Kvale, S., \& Brinkmann, S. (2009). Interviews: Learning the craft of qualitative research interviewing. Thousand Oaks, CA: Sage.

Lee, R. M. (2003). The transracial adoption paradox: History, research, and counseling implications of cultural socialization. The Counseling Psychologist, 31(6), 711-744.

Lee, R. M., Yoo, H. C., \& Roberts, S. (2004). The coming of age of Korean adoptees: Ethnic identity development and psychological adjustment. In I. Kim (Ed.), The Korean Americans: Past, present and future (pp. 203-224). Elizabeth, NJ: Hollym International Corps.

Lincoln, Y. S., \& Guba, E. G. (2003). Paradigmatic controversies, contradictions, and emerging confluences. In N. K. Denzin \& Y. S. Lincoln (Eds.), The landscape of qualitative research: Theories and issues (pp. 253-291). Thousand Oaks, CA: Sage.

Marshall, C., \& Rossman, G. B. (2006). Designing qualitative research (4th ed.). Thousand Oaks, CA: Sage.

McCarthy, D. E. (1999). Identity issues of parents who adopt children internationally. Unpublished doctoral dissertation, The City University of New York, New York.

McKay, K., \& Ross, L. E. (2010). The transition to adoptive parenthood: A pilot study of parents adopting in Ontario, Canada. Children and Youth Services Review, 32(4), 604-610.

Merriam, S. B. (1998). Qualitative research and case study applications in education: Revised and expanded from case study research in education. San Francisco: Jossey-Bass Publishers.

Moustakas, C. E. (1994). Phenomenological research methods. Thousand Oaks, CA: Sage.

Palacios, J., \& Brodzinsky, D. (2010). Adoption research: Trends, topics, outcomes. International Journal of Behavioral Development, 34(3), 270-284. 
International Journal of Child, Youth and Family Studies (2012) 4.1: 479-499

Patton, M. Q. (2002). Qualitative research and evaluation methods (3rd ed.). Thousand Oaks, CA: Sage.

Quiroz, P. A. (2012). Cultural tourism in transnational adoption: "Staged authenticity” and its implications for adopted children. Journal of Family Issues, 33(4), 527-555.

Rossman, G. B., \& Rallis, S. F. (2003). Learning in the field: An introduction to qualitative research (2nd ed.). Thousand Oaks, CA: Sage.

Shiao, J. L., Tuan, M., \& Rienzi, E. (2004). Shifting the spotlight: Exploring race and culture in Korean-White adoptive families. Race and Society, 7, 1-16.

Simon, R. J., \& Altstein, H. (1996). The case for transracial adoption. Children and Youth Services Review, 18, 5-22.

Simon, R. J., \& Roorda, R. (2000). In their own voices: Transracial adoptees tell their stories. New York: Columbia University Press.

Speziale, H. J. S., \& Carpenter, D. R. (2007). Qualitative research in nursing: Advancing the humanistic imperative (4th ed.). Philadelphia: Lippincott Williams \& Wilkins.

U.S. Bureau of the Census. (2000). Census 2000 demographic profile highlights. Retrieved from http://factfinder.census.gov

U.S. Citizenship and Immigration Services. (2003). Statistical yearbook of the Immigration and Naturalization Service, 2001. Washington, DC: U.S. Government Printing Office.

U.S. Department of State. (2010). Intercountry adoption: Statistics. Retrieved from http://adoption.state.gov/about_us/statistics.php

Vandervort, F. E., \& Sanoshy, R. B. (2009). Special issues in transcultural, transracial, and gay and lesbian parenting and adoption. In E. P. Benedek, P. Ash, \& C. L. Scott (Eds.), Principles and practices of child and adolescent forensic mental health (pp. 197-214). Washington, DC: American Psychiatric Publishing.

Vonk, M. E., Lee, J., \& Crolley-Simic, J. (2010). Cultural socialization practices in domestic and international transracial adoption. Adoption Quarterly, 13(3), 227-247.

Zhang, Y., \& Lee, G. R. (2011). Intercountry versus transracial adoption: Analysis of adoptive parents' motivations and preferences in adoption. Journal of Family Issues, 32(1), 75-98. 